\title{
Business Process Modelling and Help Systems as Part of KM in E-government
}

\author{
Alexandra Dörfler \\ Chief Information Office, Austria \\ alexandra.doerfler@cio.gv.at
}

\begin{abstract}
According to the e-Europe Action plan all traditional government services, where citizens are in contact with different public institutions have to be online by the year 2005. E-government services differ from the traditional services offered by administrations in many ways. Therefore these new processes have to be modelled, preferably using special software. Business Process Modelling is a part of Knowledge Management because understanding the processes is the basis of an organisation's knowledge. Using online services will cause a need for special "help-mechanisms" for both citizens and administrations in "one-stop-shops": Help Systems will support the users of online-services during their use. Presenting some case studies this paper will show the first steps in Business Process Modelling and adapting Help Systems for e-government scenarios in Austria.
\end{abstract}

\section{Introduction}

The implementation of e-government via online transactions in case of the traditional ways of interaction between administration and citizen calls for an extensive reorganisation of all government processes. ${ }^{1}$

"Opening" of these procedures is a maincharacteristic: procedures that have been handled internally so far will be handled byan external customer on the portal level.

Both the citizen and the civil servant need structured and accurate knowledge about the underlying processes, the procedures and competences for the implementation and application of these new processes.

The question is not "which division is responsible for the process" but "which processes are executed by whom within the process-chain". The mostly functional orientation of the internal organisation of administrative units must be considered. Government procedures must be examined concerning the possibility of non intervention by the person in charge. This reduces the expenditure and accelerates the procedures' running time. (e.g. electronic criminal record: usually no intervention of the person in charge concerning online application, online payment and online notification)

1 Government processes are processes where the interests of customers/citizens are accomplished. The main features are customer-orientation, usefulness concerning the duration of the procedure, amount of administration contacts etc.

The original version of this chapter was revised: The copyright line was incorrect. This has been corrected. The Erratum to this chapter is available at DOI: 10.1007/978-3-540-44836-5_33

M.A. Wimmer (Ed.): KMGov 2003, LNAI 2645, pp. 297-303, 2003.

(C) Springer-Verlag Berlin Heidelberg 2003 
In case of any ambiguity in executing online transactions the conception and planning of help-mechanisms for both citizens and the administration is already a big challenge. These mechanisms shall support the users while utilising e-government procedures and when they have problems with the operation of the application system. As these procedures are often used outside office hours, mechanisms that are time- and location independent are required.

Business process modelling of e-government procedures is the basis for an understanding of the mostly complex target-processes and the design of Help mechanisms.

This paper will deal with some aspects of knowledge management in egovernment. The first steps in Business Process Modelling and the design of helpsystems in Austria will therefore be illustrated.

\section{General Aspects of Business Process Modelling and Help Systems}

\subsection{Business Process Modelling (BPM)}

\subsubsection{Changes in the Future}

E-Government will change the administration processes. In the future the citizen will - instead of the official in charge - execute the procedure. Therefore the procedures have to be oriented according to the citizens' view. Furthermore these procedures have to be designed process-oriented, the administrations' functional orientation has to be considered not too much respectively adjusted to the new processes.

Besides online applications also processable attachments (XML) are available and will allow a much higher level of automatisation. Automated exchange of data with other government procedures is another module to reduce the administrations' intervention.

Online electronic payment of administrative fees occurring in a procedure is userfriendly and a factor for the reduction of the running time.

Electronic notifications (XML) with electronic signatures are another milestone in the e-government lifecycle. These notifications can be processed automatically in other government procedures. The question of electronic delivery has not been solved yet but is also a main part of the new e-government strategies.

\subsubsection{BMP in the Context of Knowledge Management}

The design and revision of business processes is the subject of BPM. In the course of a process knowledge is currently generated. At the same time the process accesses on knowledge.

Knowledge about the process, the different functions and their coherences is called process knowledge. This knowledge can be used for optimising, customer orientation and acceleration of the process. Knowledge needed for a certain step of the process is called functional knowledge. 
The integrated management of knowledge and processes can be defined as administration and control of organisational processes. Besides there are a certain abilities, skills and knowledge generated.

\subsubsection{Why BPM?}

In many parts of the administration the actual processes are documented inadequately. The complex processes cannot be redesigned by one person alone. Different divisions of an organisation like operating department, IT department and often consultants have to work together. The use of software tools facilitates communication for the members of the "process-management-team".

Transparent procedures allow the concerned persons to understand the processes and coherences. Every concerned person identifies his or her task along the process chain (citizen, system, administration).

Documenting and analysing the organisations' processes is the basis for efficient organisational knowledge. Graphical illustration brings objectivity and clarity.

Reduction of costs can only be achieved when knowing the potential of economisation which is located by analysing and possibly simulating the target process model in comparison with the actual process model.

\subsubsection{Software Tools}

For the modelling of simple processes a graphic tool like MS Visio is sufficient. The majority of processes deal with complex processes where a business process management tool is necessary. BMP software supports the analysis, the modelling of the processes, documentation and simulation of business processes, organisational structures and information systems with integrated aspects activity-based costing etc.

The amount of BPM software offered is high. They differ extremely in functional range and complexity. Some of these tools are already in use in the Austrian administration (e.g. ARIS, Adonis). The focus should be put on user friendliness, to enable also non specific users who do normally not have a good knowledge of these tools to work with them.

Main characteristics of a BPM software tool are the following modules; modelling and optimisation of processes, where optimising comprises the possibility of simulation and analysis of workload. Standard interfaces (import/export) to workflow management software on the one hand and to office products for documentation and acquisition of data on the other hand as well as support in making the documentation are desirable. Finally far-reaching flexibility in configuration is important to adjust the software to the specific needs of public administration.

\subsection{Help Systems}

Some years ago Help Systems were printed handbooks where the users could look for the desired information. Later they were the first online handbooks.

"Help" in e-government procedures can be manifold; it reaches from expertsystems, to call centres, web-phone, virtual agents (these are programmes that present different topics, lead trough a guided-tour or answer to questions of users), forums, chats, newsgroups (moderated or not), FAQs and collaborative desktops (which is the 
collaborative working on a specific case/procedure, collaborative browsing or filling in of government forms).

Modern Help systems offer besides different search mechanisms in the system context-sensitive help (Information to the input field). The answers delivered help the users to avoid timely search activities, but they do not always answer the question raised originally.

Many requests come from the applications that are not designed user-friendly. ITdesigners do not often realize the difficulties for non-experienced users that arise from insufficiencies of the system.

Modern Help-mechanisms allow the free formulating of questions in original spoken language. These systems are self-learning? once a question is answered (e.g. by the call center) it is integrated in the system as answer for future questions concerning the same topic. By collecting these questions and requests FAQs are generated, administered and updated automatically. These systems are able to cover a high amount of help-requests after a short introduction period, because usually a limited number of different requests have occurred in a certain period of time. The level of automatisation determines the size of the call center. When users do not get a satisfying answer via these mechanisms the request should be routed to the call center where in a first step a written dialogue with a call center agent via chat-mechanisms should take place. Future answers are generated and can be processes automatically by the system.

Help-text-blocks that are normally provided in e-government sites are often not applicable and do not support the citizen. Therefore the drop-out rates are high, because once a citizen was not able to do her or his government procedures online she or he will choose again the traditional way of interaction with the administration. Users with these experiences will avoid e-government procedures for a very long time.

\section{Case Studies /Pilot Projects}

\subsection{E-scholarship (BPM)}

This project was initiated by Microsoft and Siemens. The company offered the Austrian administration to support the implementation of new e-government procedures.

The reasons for choosing "e-scholarship" were the high level of e-skills of students, a high amount of penetration of the student card and that a large number of public access points will be installed in the university institutes in the future. The goal was to have a signed electronic application for a scholarship for a student until fall 2003. Also the act ruling scholarships was one of the first who allowed applying for scholarship by electronic means using secure electronic signatures. To deliver first results for this date the e-application was based on the traditional (paper-) application

2 Definition: a special capability of a device or machine such that it can improve its capability in decision-making as programmed with instructions and based on information received, new instructions received, results of calculations or environmental change. 
which means that the order of entry masks in the e-application was adjusted to the "single steps" in the traditional application.

In the course of the implementation of "e-scholarship" the project and working group "BPM of e-scholarship" started. This was argued with the changing of processes in the "scholarship authority" because of e- scholarship. The analysis of the business processes was done by documenting the facts and by examining the entry masks that already existed. Interviews with the persons in charge showed that some of them had different views about the scholarship-procedure. By visualising the procedure with a software tool and by common description of the fact the team agreed on a common view. Most of the time was spent on discussion.

\subsubsection{Results}

Phase 1

- The order of entry masks for the initial application was changed.

- Facts and basic data were queried and acquired only once.

- Data exchange with other authorities has to be considered and established.

- Due to the fact that the application is very complex, the aspects of overview and storage have to be considered.

- Once data has been saved and displayed later, the problem of identification arrises.

- Data from other procedures have to be requested and provided online.

- The question of signing of notifications is still unsolved.

Phase 2

- The procedure was modelled as an online dialogue from application to notification.

- Data of the Population Register, the social security insurance, income data of the financial authorities and data (study success, etc.) of the university were integrated.

- First thoughts were spent on automatical processing of the procedure without any intervention of the administration.

- The possibility of requesting the status of the procedure for the student is planned.

Phase 3

- Data saved once can only be displayed with secure identification; therefore the use of the citizen card is unavoidable.

- This applies also to the requesting the status of the procedure.

- The initial application was structured in several blocks which consist of several pages. Additional mechanisms are necessary for navigating trough the application. A survey-mask is necessary.

- The data must be signed electronically at the end.

\subsection{Finanz-Online (Help System)}

As already mentioned before Help-text-blocks that are normally provided in egovernment sites are often not applicable and do not support the citizen. Therefore the drop-out rates are high, users with these experiences will avoid the e-government procedures for a very long time.

"Finanz-online" (http://www.bmf.gv.at/egov/fonline/_start.htm) is the method of electronic data transfer within the Austrian financial administration based on Internet technology. Citizens can to do their tax adjustments since the beginning of 2003. 
It was planned to install a proactive help-system based on a knowledge database for "Finanz-online". A help-system like this is independent of the application system and is linked at specific positions. All standard help-texts can either remain in the application system or be integrated in the independent help-system.

The questions and answers occurring when working with the application are developed with a determined number of users during the pilot-phase and are then released for operation. The application can supply a customer-friendly help-system: all requests can be answered.

Another aspect of knowledge-based Help-mechanisms is the possibility of free formulating of questions which means that the user does not have to navigate trough a help-system and look for the corresponding answers but that he can formulate with his own words and terms his question. He must not be aware of "administrative language". The user gets a list of 1-n corresponding answers (percentage of probability ) and selects one answer. Additionally he clicks if the answer was suitable for him. With this information the system can self-learning build up knowledge; FAQs are generated automatically.

The reason why this project has not yet started is the high licence fee for software and the consulting fees for the implementation of the Help-Mechanisms.

\section{Conclusion}

E-Government means an enormous change for the administration and for the authorities on all levels.

By the end of 2002 the administration was not yet fully aware of the importance of Business Process Modelling and of the designing of help-systems for planned egovernment services.

BPM must be started as soon as possible. The later a BPM-project starts, the more resistance comes from persons and organisations involved. BPM of e-government procedures is the basis for the understanding of these very complex processes and a basic requirement for the design of help-systems.

Awareness must be raised among the Administration showing the advantages of BPM software tools. The Austrian Chief Information Office is promoting the use of BPM-software and will assist interested administrative units in working with these tools. Future projects are BPM for "paperless foreign trade administration" and for "Criminal record".

To meet the goals of the e-Europe Action plan government services have to be online by the year 2005. Complex e-government procedures must be designed using BPM software to reduce the procedures` running time, to reduce the administrations` expense and to run automatically.

Complex procedures must also be supported with the use of help-systems, based on knowledge about these processes. The two pilot-projects presented were the first in this new area. Many others will follow to make e-government successful. 


\section{References}

1. Federal Ministry of Public Service and Sports, Autria, 17.9.2002, „, Bilanz der Verwaltungsreform"

2. Bullinger, Hans-Jörg, Fraunhofer IAO, Knowledge meets Process, Stuttgart 2001

3. Meir, Joel „Prozessmanagement als Grundlage für integriertes eGovernment“, Bulletin des Kompetenzzentrums eGovernment der Berner Fachhochschule, «eGov Präsenz» Ausgabe $02 / 2001$

4. Schaffroth, Marc, „Welches Informationsmanagement braucht eGovernment?, Bulletin des Kompetenzzentrums eGovernment der Berner Fachhochschule, «eGov Präsenz» Ausgabe 02/2001

5. Seifried, Patrick, Eppler J., Martin, Evaluation führender Knowledge Management Suites; NetAcademy Press, 2000

6. Traunmüller, Lenk, „Electronic Government“ First International Conference, EGOV 2002, Aix-en Provence, Sept. 2002

7. Wimmer, Maria, Wissensmanagement in eGovernment, Bulletin des Kompetenzzentrums eGovernment der Berner Fachhochschule, «eGov Präsenz» Ausgabe 01/2001

8. Wimmer Maria, 2002, Tagungsband zum ersten egov Day des Forums egov.at. 